\title{
PERDAS AUDITIVAS CONDUTIVAS
}

\author{
CONDUCTIVE HEARING LOSS
}

Miguel A. Hyppolito

Docente. Divisão de Otorrinolaringologia. Departamento de Oftalmologia, Otorrinolaringologia e Cirurgia de Cabeça e Pescoço da Faculdade de Medicina de Ribeirão Preto - USP.

Correspondência: Miguel Ângelo Hyppolito. Divisão de Otorrinolaringologia. Departamento de Oftalmologia, Otorrinolaringologia e Cirurgia de Cabeça e Pescoço. Faculdade de Medicina de Ribeirão Preto - USP. Avenida Monte Alegre, 3900. Ribeirão Preto - SP Brasil. CEP: 14049-900; E-mail: mhyppolito@uol.com.brou mahyppo@fmrp.usp.br

Hyppolito MA. Perdas auditivas condutivas. Medicina (Ribeirão Preto) 2005;38 (3/4): 245-252.

RESUMO: O sistema auditivo é constituído pelas orelhas externa, média e interna e pelas vias auditivas no sistema nervoso central. A membrana timpânica tem como função amplificar a pressão sonora, permitindo uma amplificação de sons. A orelha média compreende a cavidade timpânica composta pela membrana timpânica (camadas intermediária e interna), cadeia ossicular com seus músculos e ligamentos, a tuba auditiva, o adito, o antro e as células mastóideas. Conhecendo-se as estruturas das orelhas externa e média e sua fisiologia na transmissão sonora, pode-se reconhecer o que alterações neste sistema trazem de prejuízos para a função auditiva no ser humano, constituindo assim quadros clínicos diversos que cursam com perdas auditivas condutivas.

Descritores: Orelha Externa. Orelha Média. Audição. Otite. Perda Auditiva. Condutos Auditivos.

\section{1- INTRODUÇÃO}

Para os seres humanos a audição é um sentido de importância vital por ser a base para a comunicação e assim, para socialização e inter-relações pessoais. Com o desenvolvimento filogenético houve a necessidade do aperfeiçoamento do sentido da audição. O sentido da visão ficou prejudicado pelo relevo e vegetação à vida terrestre, necessitando, o homem de um sistema auditivo refinado que permitisse a percepção da aproximação de inimigos, a socialização e a reprodução. Pelas diferenças na propagação dos sons da água para o ar, houve a necessidade de uma adaptação do sistema auditivo para minimizar a perda de energia na transformação da energia mecânica sonora para o impulso elétrico percebido pelo sistema nervoso central dos seres da vida terrestre. Nos seres humanos e nos mamíferos o grau de refinamento do sistema auditivo permite um aproveitamento de Energia com mínima perda ${ }^{1}$.

O sistema auditivo é constituído pelas orelhas externa, média e interna e pelas vias auditivas no sistema nervoso central. A orelha externa compreende o pavilhão auricular, o meato acústico externo e a camada superficial da membrana timpânica, com a função de amplificar a pressão sonora, proteger as orelhas média e interna e melhorar a localização de sons, permitindo uma amplificação de sons na faixa de freqüências de $1500 \mathrm{~Hz}$ a $7.000 \mathrm{~Hz}$. A orelha média compreende a cavidade timpânica, composta pela membrana timpânica (camadas intermediária e interna), cadeia ossicular com seus músculos e ligamentos, a tuba auditiva, $\mathrm{o}$ adito, $\mathrm{o}$ antro e as células mastóideas ${ }^{2,3}$. (Figura 1) 


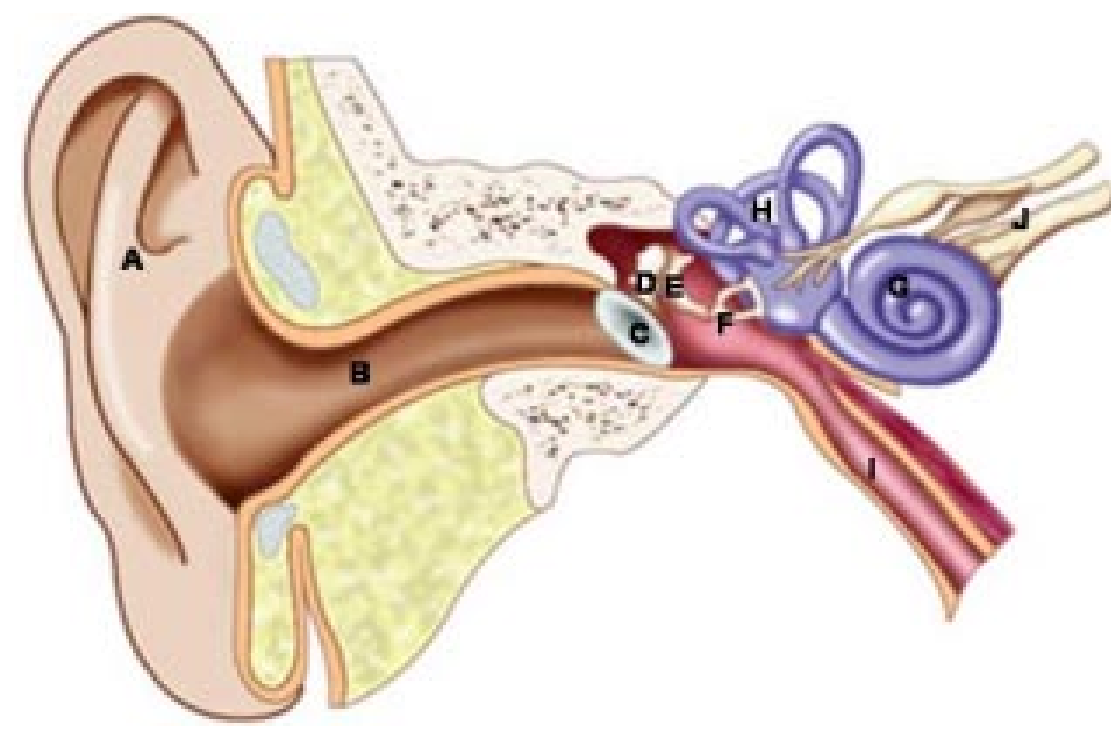

Figura 1: Esquema representativo das orelhas externa, média e interna e suas estruturas anatômicas. (A - pavilhão auricular; B - meato acústico externo; C - membrana timpânica; D - martelo; E - bigorna; F - estribo; G - cóclea (labirinto anterior); H - Canais semicirculares (labirinto posterior); I - tuba auditiva; $\mathrm{J}$ - nervo vestíbulo coclear).
Considerando a conservação da energia no sistema auditivo, as orelhas externa e média são responsáveis pela conservação da energia de 999 milésimos em trânsito do meio aéreo para o meio líquido do labirinto (orelha interna). Esta função é mais bem desenvolvida pela orelha média que é um elemento transformador de impedâncias, dependente de fatores como massa, rigidez e atrito ${ }^{3}$.

Conhecendo-se as estruturas das orelhas externa e média e sua fisiologia na transmissão sonora, pode-se reconhecer o que alterações neste sistema trazem de prejuízos para a função auditiva no ser humano, conhecidas como perdas auditivas condutivas. (Figura 2)

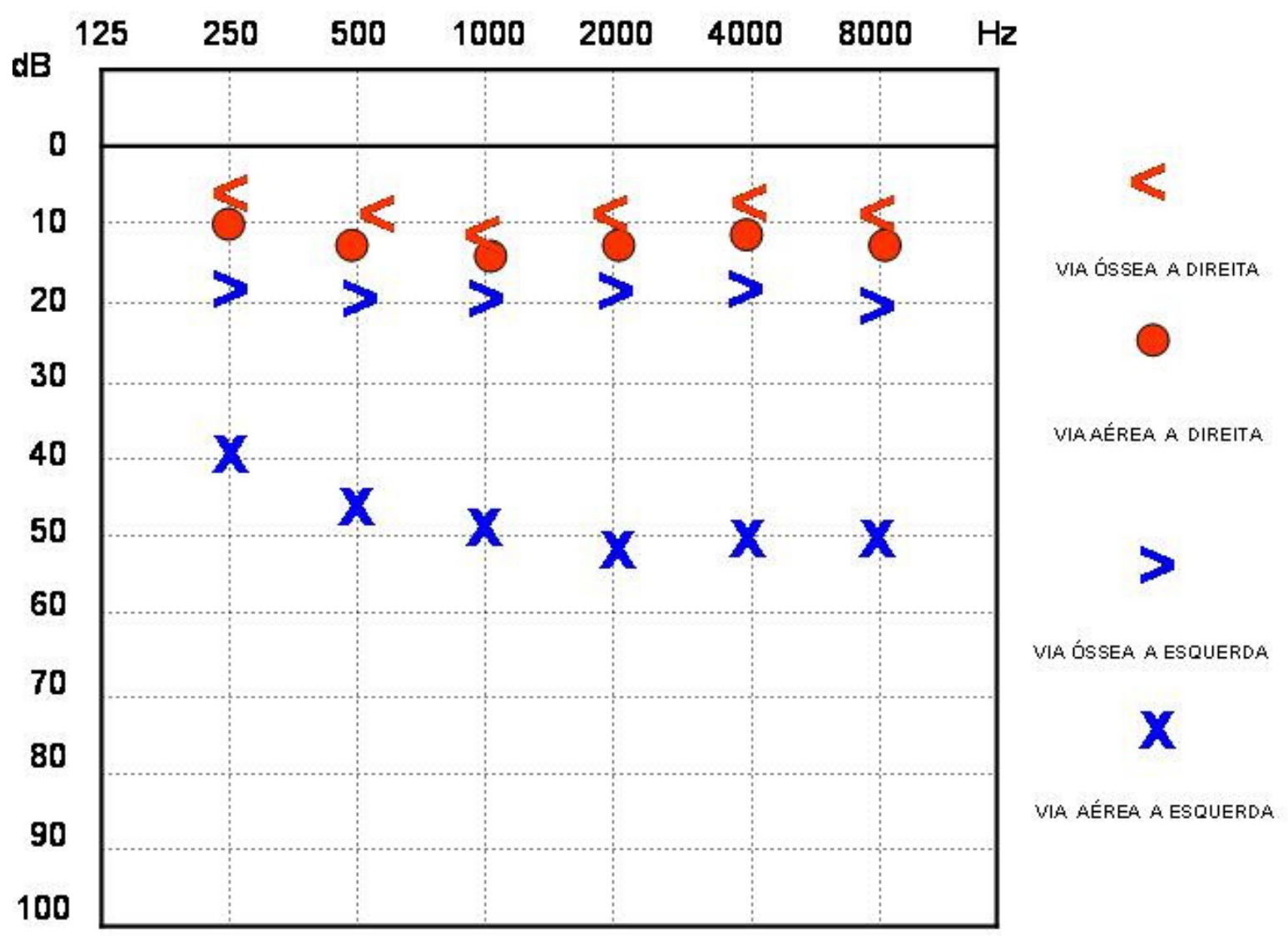

Figura 2: Gráfico representativo de um exame de audiometria tonal limiar, mostrando curva com limiares de normalidade a direita e exemplo típico de perda auditiva condutiva a esquerda de grau moderado. Notar o "gap" existente entre a via óssea (normal) e aérea a esquerda. 


\section{2- SITUAÇÕES E DOENÇAS QUE CURSAM COM PERDAS AUDITIVAS CONDUTIVAS}

\section{1- Distúrbios do pavilhão auricular e meato auditivo externo (MAE) - orelha externa}

As patologias de orelha externa causam perda auditiva de condução por levarem a uma obstrução mecânica à condução do som. Além dos processos infamatórios, alterações congênitas que evoluem com malformações de pavilhão auricular e atresia ou agenesia de meato acústico externo impedem a chegada da onda sonora à orelha média. Entre elas merecem atenção às relacionadas a malformações do primeiro arco e primeiro sulco branquial, resultando em: anormalidades do pavilhão auricular; atresia do conduto auditivo externo ósseo, com ou sem associação de anormalidades no martelo ou bigorna e anormalidades na mandíbula ${ }^{3}$.

Quanto às malformações congênitas da orelha que alteram o sistema de condução do som, Colman classifica em três grupos básicos ${ }^{1,3}$ :

Grupo I: Anomalias menores. O canal auditivo externo está presente, é estreito, mas permeável. A cadeia ossicular pode estar fixa, principalmente o estribo. É o tipo menos comum de malformação.

Grupo II: Anomalias maiores. O pavilhão auricular está com malformações evidentes, o meato auditivo externo ósseo está ausente. A orelha média também apresenta anormalidades variadas. São os casos mais frequientes.

Grupo III: Anomalias na pneumatização do osso temporal com malformações na orelha interna presentes.

O tratamento destas condições visa restabelecer a condução do som através de procedimentos cirúrgicos que são indicados nas anomalias do grupo I e no grupo II somente se bilaterais, sendo contraindicadas para o grupo III. São cirurgias difíceis, realizadas em vários tempos cirúrgicos e com resultados bastante variados, com resultados satisfatórios para as malformações do grupo I.

Quanto às doenças adquiridas da orelha externa, as mais comuns são as otites externas, com uma incidência de 5 a $20 \%$ no verão e que levam à perda auditiva por edema do meato acústico externo ${ }^{4}$.

Além disso, outras situações podem induzir a perda auditiva condutiva:

a) Corpos estranhos do meato acústico externo.

Podem ocorrer em qualquer idade, mais $55 \%$ ocorrem em crianças até 15 anos de idade e podem ser inertes ou vivos, chegando ao MAE de forma vo- luntária ou involuntária. O tratamento visa à remoção adequada do corpo estranho, evitando-se lesões iatrogênicas do mesmo ou da membrana timpânica e/ou cadeia ossicular ${ }^{5,6}$.

b) Traumas e ferimentos do pavilhão e MAE. A perda auditiva condutiva ocorre por edema e ou lacerações do MAE, podendo haver estenose do mesmo, quando a porção cartilaginosa é comprometida. O tratamento é cirúrgico e de difícil resolução, com recidivas frequientes das estenoses ${ }^{7,8}$.

c) Otoematoma. São na maioria de etiologia traumática, ocorrendo de forma espontânea em pacientes portadores de discrasias sanguíneas. Pode ocluir o MAE, o que não é comum ${ }^{7,8,9}$.

d) Queimaduras. Podem levar a estenose do MAE e lesão da membrana timpânica como complicações, além de infecção secundária ${ }^{8}$.

e) Pericondrite. Infecção localizada na cartilagem da orelha externa, com evolução lenta. Evolui com necrose da cartilagem, o que favorece sua deformidade, favorecendo assim a oclusão do MAE e perda auditiva condutiva ${ }^{4,7,9}$.

f) Rolhas (Tampões) de cerume ou epidérmicos. O cerume é composto de descamação epitelial, secreção sebácea e produto de glândulas ceruminosas. Os sintomas freqüentes são hipoacusia súbita, autofonia, otalgia e vertigem e/ou zumbidos em alguns casos. Os tampões epiteliais são compostos por restos epiteliais queratinizados, aderidos às paredes do MAE. São de origem idiopática, com freqüente potencial de recidiva ${ }^{4,7}$.

g) Colesteatoma de MAE. Gera sintomas de otalgia crônica monótona, unilateral com ocasional otorréia de odor fétido, geralmente a audição é normal, o que depende da obstrução do MAE pelo colesteatoma. A membrana timpânica não está comprometida e há erosão óssea do MAE. O tratamento depende de sua remoção cirúrgica, bem como de qualquer osso necrótico local ${ }^{9,10}$

h) Dermatites. Causam preferencialmente prurido, mas existe hiperemia ou palidez da pele do MAE, edema, vesículas e exsudatos, reduzindo a luz do MAE, favorecendo assim a hipoacusia condutiva. Podem evoluir para uma forma de otite externa crônica recidivante ${ }^{4,8,9}$.

i) Otomicose. É o comprometimento do MAE e da membrana timpânica por fungos (Aspergillus e Candida), de evolução lenta, sendo o sintoma mais comum o prurido. A redução auditiva depende do grau de comprometimento da luz do MAE e da associação com descamação epitelial e cerume ${ }^{4,9,11}$. 
j) Tuberculose e Leishmaniose. Lesões granulomatosas que podem comprometer o MAE e orelha média, sendo esta mais comum na tuberculose, levando a perda auditiva condutiva por oclusão do MAE ou comprometimento da membrana timpânica e lesão da cadeia ossicular ${ }^{4,9,12}$.

k) Otite externa localizada. Compromete os folículos pilosos e sebáceos do terço externo da orelha externa, sendo causada por estafilococos. Leva a otalgia intensa e aguda e eventual hipoacusia dependendo da obstrução do $\mathrm{MAE}^{4,9,13}$.

I) Otite externa difusa aguda. Infecção bacteriana causada principalmente pelo Staphilococcus, Streptococcus, Klebsiella pneumoniae, Proteus mirabilis e Pseudomonas aeruginosa. Causa otalgia intensa, otorréia e sensação de plenitude auricular e hipoacusia, dependendo do edema e da intensidade e qualidade da otorréia no $\mathrm{MAE}^{4,7,9,13}$.

m) Otite externa granulosa. Inflamação do terço interno do MAE, caracterizado por tecido de granulação na pele deste ou na camada superficial da membrana timpânica, causando otalgia, otorréia e hipoacusia condutiva. Pode comprometer toda a membrana timpânica. Tem boa evolução com o tratamento local $1^{4,9,13}$.

n) Otite externa maligna. Doença infecciosa grave que pode comprometer idosos, diabéticos descompensados e imunodeprimidos, causada pela Pseudomonas aeruginosae uma doença necrosante do MAE que tem caráter invasivo para a região parotídea, mastóide, orelha média e base do crânio, podendo atingir índices de mortalidade elevados. São sintomas comuns otalgia, otorréia e hipoacusia que pode variar de condutiva a mista na dependência da toxicidade e evolução do processo invasivo. É necessário o tratamento local associado ao uso de antibióticos sistêmicos e, em alguns casos, o debridamento cirúrgico ${ }^{4,9,14}$.

o) Estenose adquirida do MAE. Decorre de origem idiopática ou secundária a trauma, inflamação crônica, estenose térmica ou estenose pós-operatória do MAE. É rara e leva a perda auditiva condutiva de grau variado ${ }^{4,7,9}$.

p) Exostose do MAE. É a hiperplasia do periósteo na porção óssea do MAE em indivíduos que nadam e mergulham constantemente em água fria. É geralmente bilateral. Os sintomas decorrem da obstrução do MAE, principalmente levando a retenção de cerume ou descamação epitelial, infecção secundária ou hipoacusia condutiva. $\mathrm{O}$ tratamento é cirúrgico ${ }^{4,7,9}$.

\section{2- Distúrbios da orelha média}

\subsection{1- Otite média aguda (OMA)}

A OMA é uma inflamação da orelha média que cursa com sinais e sintomas, caracterizados por otalgia, febre, mal estar geral e irritabilidade, hipoacusia e desequilíbrio, queda do estado geral, anorexia, cefaléia e por vezes otorréia, dependendo da faixa etária acometida. Tem início rápido e pode evoluir para complicações intratemporais e intracranianas com seqüelas a curto, médio e longo prazos. É responsável pelo atendimentpo de 1/3 em consultas médicas nos EUA e por $38 \%$ das prescrições de antibióticos neste País ${ }^{15}$.

Tem alta prevalência com incidência entre $6 \mathrm{e}$ 24 meses de idade e entre os 4 e 7 anos de idade, o que varia de acordo com as condições sócioeconômicas, a variação climática local e sazonalidade ${ }^{16,17}$.

A OMA pode ser classificada em subtipos: viral, bacteriana com ou sem supuração, necrosante aguda, alérgica aguda, tuberculosa e do lactente. Pode também ser secundária a trauma ou fúngica ${ }^{18}$.

Na patogênese da OMA estão envolvidos a infecção (agente infeccioso), condições imunológicas do hospedeiro, disfunção tubária, alergia e condições socioeconômicas, como frequiência a berçários, escolas, parada precoce no aleitamento materno e fumo passivo. Os agentes bacterianos mais frequientes são o Streptococcus pneumoniae (20-40\%), Haemophilus influenzae (10-30\%), Moraxella catarrhalis (10-20\%) e Streptococcus pyogenes e Staphilococcus aureus (2-3\%), podendo ainda haver a presença de bactérias entéricas e $S$. aureus em neonatos ${ }^{16,19,20}$.

O diagnóstico é realizado pelo quadro clínico e exame físico adequado e completo, com especial atenção pela otoscopia, com visualização de toda a membrana timpânica, após a limpeza adequada do $\mathrm{MAE}^{15,18}$.

A perda auditiva na OMA pode ocorrer e geralmente é transitória em decorrência do acúmulo de secreção na orelha média, o que dificulta a transmissão do som pela membrana timpânica e cadeia ossicular. No entanto, devido à toxicidade de produtos bacterianos e inflamatórios liberados próximos à janela redonda ou ao próprio agente etiológico envolvido, pode ocorrer perda auditiva neurossensorial ou mista, devido ao comprometimento coclear ${ }^{15,16}$.

O tratamento é realizado no nível ambulatorial dependendo das condições gerais do paciente, com antibióticos por 10 dias e medidas sintomáticas para febre, dor e mal estar. Complicações devem ser trata- 
das em ambiente hospitalar com antibióticos endovenosos e muitas vezes medidas cirúrgicas ${ }^{15,16,18}$.

Além dos episódios isolados, podem ocorrer episódios de OMA recorrente, sendo mais comuns em crianças. É caracterizada como sendo a ocorrência de 03 ou mais episódios de OMA bem documentados em 6 meses ou 04 ou mais episódios em 12 meses. Estima-se que $75 \%$ de todas as crianças terão pelo menos 01 episódio de OMA antes dos 05 anos de idade e que destas $30 \%$ terão 03 ou mais episódios antes dos 03 anos, as quais $25 \%$ terão uma tendência a apresentar OMA recorrente. As condições que favorecem a OMA recorrente são mais comuns no sexo masculino entre os 06 e 18 meses, sendo mais freqüentes no inverno, coincidindo com o aumento na incidência das infecções de vias aéreas superiores. Tem como fatores de risco a frequiência a creches e berçários precocemente, irmãos com história de otites, curta duração do aleitamento materno, posição da amamentação com a mamadeira, tabagismo, atopia e presença de refluxo gastro esofágico - faríngo laríngeo patológico. Nestes casos, as perdas auditivas recorrentes agudas e a persistência de secreção na fenda auditiva, contribuem de forma significativa para alterações de fala e linguagem nesta criança, levando a alterações comportamentais e de aprendizado ${ }^{17,18}$.

\subsection{2- Otites médias crônicas (OMC)}

As OMC são definidas sob os aspectos clínico, temporal e histopatológico. É o processo inflamatório da orelha média com duração não inferior a 3 meses, associada a alterações teciduais irreversíveis na dependência da intervenção precoce ${ }^{15,21,22}$.

As otites médias foram classificadas por Bluestone e Kenna em 1988 como Otite média crônica supurativa aguda ou crônica e como Otite média crônica não-supurativa, serosa ou secretora (mucóide). Já as OMC podem ser classificadas em não-específicas (não colesteatomatosa, colesteatomatosa e OMC silenciosa) e específicas (tuberculosa, actinomicótica, luética entre outras $)^{15}$.

\subsection{3- Otite média crônica secretora e serosa}

Do ponto de vista clínico quanto a sinais e sintomas as Otites médias não supurativas, com evolução maior que 3 meses, portanto crônicas, cursam tipicamente com perda auditiva condutiva, sem a presença de dor, com a sensação de plenitude auricular ("ouvido cheio") ou sensação de "deslocamento de líquido no ouvido" e autofonia. A hipoacusia geralmente é bilateral nas crianças ( $80 \%$ dos casos) e moderada entre 40-45 dB. Excepcionalmente pode-se encontrar hipoacusia neurossensorial concomitante ${ }^{21 / 24}$.

O tratamento baseia-se em melhorar as condições da tuba auditiva, favorecendo a absorção e ou drenagem do conteúdo presente na fenda auditiva o que muitas vezes necessita de timpanotomia e colocação de tubo de ventilação ${ }^{21 / 24}$.

\subsection{4- Otite média crônica não colesteatomatosa}

Neste item existem as doenças chamadas de tubotimpânicas e as aticoantrais. As primeiras têm duas formas de apresentação com perfuração permanente da membrana timpânica e a mucosite tubotimpânica crônica ${ }^{25,26,27}$.

Perfuração permanente: caracterizada pela presença de uma perfuração ou solução de continuidade timpânica limitada à parte tensa da membrana timpânica. Na maior parte do tempo à orelha permanece seca, sem otorréia, existe a queixa de otorréia intermitente, sem odor, sem febre ou otalgia, concomitante a infecções do trato respiratório superior ou a contaminação por banhos de piscina, rio ou mar. A perda auditiva é tipicamente condutiva de intensidade variável dependendo de fatores como o tamanho e localização da perfuração timpânica e de alterações na cadeia ossicular e repercussão dos processos inflamatório e infeccioso sobre a orelha interna. Nas fases de agudização e contaminação são utilizadas gotas auriculares não ototóxicas e é recomendável o tratamento cirúrgico com o objetivo de fechar a perfuração, evitando quadros de otorréia e melhorando a audição ${ }^{28 / 31}$.

Mucosite tubotimpânica: caracteriza-se pela presença de otorréia mucopurulenta de longa duração acentuada pelos processos de infecção de vias aéreas superiores, geralmente com perfurações amplas e comprometimento da cadeia ossicular. A mucosa da orelha média encontra-se com constante processo inflamatório que pode exteriorizar-se na forma de um pólipo inflamatório. Este quadro pode progredir, evoluindo para uma otite colesteatomatosa, principalmente na presença de uma perfuração marginal ${ }^{28,29,32}$.

A perda auditiva é condutiva, sendo que não é incomum uma perda mista em decorrência do processo inflamatório infeccioso persistente na fenda auditiva. São necessários exames de imagem para avaliar 
as condições da região atical e mastóidea. O tratamento depende de tentar secar a orelha com gotas auriculares ou cauterizações e o tratamento cirúrgico, necessitando na maioria dos casos a realização de uma timpanomastoidectomia ${ }^{33 / 37}$.

Otite média crônica silenciosa: é definida como alterações inflamatórias irreversíveis na orelha média com a presença de membrana timpânica íntegra. A presença deste processo na orelha média leva a danos a orelha interna carreados pela janela redonda, acarretando assim perdas auditivas neurossensoriais ou mistas ${ }^{38,39}$.

\subsection{5- Otite média crônica colesteatomatosa}

É definido como sendo a presença de epitélio escamoso estratificado queratinizado sobre uma matriz de tecido fibroconectivo dentro da orelha média. Tem características líticas e de migração pela liberação de citoqueratinas e citocinas na mucosa alterada ${ }^{40,41}$.

$O$ colesteatoma pode ser congênito ou adquirido, primário ou secundário. O primário ocorre por aspiração da parte flácida da membrana timpânica e o secundário de uma migração de pele por uma perfuração timpânica ou por uma atelectasia da membrana timpânica. O diagnóstico é realizado pela anamnese com uma otorréia contínua e fétida, geralmente com otalgia que pode ser observada a otoscopia juntamente com descamações (debris), pólipos e/ou atelectasias. O comprometimento auditivo geralmente é condutivo ou misto, de graduação variável dependendo do grau de comprometimento da cadeia ossicular e da orelha interna ${ }^{41,42}$.

É necessária a realização de tomografia computadorizada do osso temporal para definir a extensão da lesão e suas potencias complicações. O colesteatoma é uma doença grave que deve ser tratada precocemente antes de acarretar algum tipo de complicação extra ou intracraniana, podendo ser prevenida pelo tratamento das doenças que acarretam alterações da tuba auditiva ${ }^{42,43,44}$.

\subsection{6- Outras doenças que acarretam perda auditiva condutiva}

Timpanosclerose: é uma afecção comum nos indivíduos portadores de otite média crônica supurativa, otites médias agudas recorrentes e otite média crônica secretora, com ou sem tubos de ventilação. De etiopatogenia desconhecida, caracteriza-se por áreas de tecido colágeno avascular que sofre degeneração hialina com depósito de cálcio e neoformação osteocartilaginosa. Compromete a membrana timpânica e outras áreas da orelha média como a cadeia ossicular, levando a uma perda auditiva condutiva ${ }^{45,46}$.

Otosclerose: é definida como um processo patológico primário, osteodistrofia localizada, da cápsula ótica, raramente envolvendo a cadeia ossicular, podendo gerar alterações secundárias a audição com perdas auditivas condutivas, neurossensorial ou mista. Geralmente compromete os ossos temporais bilateralmente e de forma simétrica. Existe a participação de um fator genético na otosclerose, autossômico dominante e de penetrância variável, entre 25 e $40 \%$, existindo uma maior incidência no sexo feminino. $\mathrm{O}$ tratamento pode ser através da cirurgia de estapedotomia ou estapedectomia e em alguns casos, principalmente com perdas auditivas neurossensoriais ou com vertigem associada, pode ser indicado o aparelho de amplificação sonora ${ }^{47,48,49}$.

\subsection{7- Traumas do osso temporal, membrana timpânica e cadeia ossicular}

Podem ocorrer de forma direta a membrana timpânica e cadeia ossicular, como por exemplo, o trauma por "cotonete" ou grampo de cabelo, acarretando perda auditiva condutiva de intensidade variável, dependendo do local comprometido ${ }^{50}$. Os traumas de osso temporal podem ocorrer por acidentes com trauma craniano direto ou por objetos perfuro cortantes. Pode ser aberto ou fechado. A fratura do osso temporal pode estender-se ao meato acústico externo, a membrana timpânica, cadeia ossicular, cóclea, vestíbulo e nervo facial. A perda auditiva é uma das complicações deste tipo de lesão podendo ser condutiva ou neurossensorial, de grau variável, reversível ou irreversível. As perdas condutivas ocorrem por hematoma ou perfuração da membrana timpânica, hemotímpano e/ou lesão da cadeia ossicular em diferentes níveis. Os traumas de osso temporal têm ainda como complicações: paralisia facial, fístula liquórica, meningite, colesteatoma secundário, vertigem e perda auditiva. O tratamento pode envolver um procedimento cirúrgico otológico para tratamento do nervo facial (descompressão), correção de fístulas ou reconstrução de cadeia ossicular, sendo que os casos de perda auditiva neurossensorial bilateral podem necessitar de aparelho auditivo ${ }^{51 / 54}$. 
Hyppolito MA. Conductive hearing loss. Medicina (Ribeirão Preto) 2005;38 (3/4): 245-252.

Abstract: The auditory system components are external ear, middle ear, inner ear and central auditory pathways. The timpanic membrane and ossicular chain amplify the sounds to inner ear, beeing an efficient energy conservatory system.

Alterations on this system will perform a hearing loss, with various pathological conditions on external and middle ears that ends to conductive hearing loss.

Keywords: Ear, External. Ear, Middle. Hearing. Otitis. Hearing Loss. Auditory Pathways.

\section{REFERÊNCIAS BIBLIOGRÁFICAS}

1 - Albernaz PLM. Elementos de psicoacústica. In: Munhoz MSL, Caovilla HH, Silva MLG, ed. Audiologia clínica. São Paulo: Atheneu; 2003. Série Otoneurolgia, v. 2, p 11-102.

2 - Kirachae I. Physiology of the middle ear, including Eustachian tube. In: Papparella MM, Shumrick DA. Otolaryngology. Philadelphia: W.B. Saunders; 1973. v. 2, p. 22-4

3 - Hungria H. Anatomia. In: Hungria H. Otorrinolaringologia. Rio de Janeiro: Revinter; 2000. p.243-363.

4 - Guatimosim MHE. Doenças da orelha externa. In Campos $\mathrm{CAH}$, Olival $\mathrm{HO}$, ed. Tratado de otorrinolaringologia. São Paulo: Roca; 2003. v. 2, p. 3-20

5 - Bergstrom L. Diseases of the external ears. In: Bluestone CD, Stool SE. Pediatric otolaryngology. Philadelphia: W B. Saunders; 1983. p. 347-52.

6 - Guatimosim MHE. Doenças do ouvido externo. In: Bento RE, Miniti A, Marone SAM. Tratado de otologia. São Paulo: EDUSP;1998. p. 149-67.

7 - Hungria H. Patologia do ouvido externo. In: Hungria H. Otorrinolaringologia. Rio de Janeiro: Guanabara- Koogan; 1995. p. 307-315.

8 - Sampaio AP, Castro RM, Rivitti EA. Dermatologia básica. $3^{\text {a }}$ ed. São Paulo: Artes Médicas, 1983. cap 20, p. 271- 278.

9 - Sperling N, Howard R, Angeli RD, Santos LEG, Costa SS. Doenças da orelha externa. In: Cruz OLM, Costa SS. Otologia clínica e cirúrgica. Rio de Janeiro: Revinter; 1999. cap. 5, p. 121-36.

10 - Caldas N. Otite média colesteatomatosa. In: Sih T. Otologia e Audiodiologia em Pediatria. Rio de Janeiro: Revinter; 1999. p. 99-105.

11 - Stern JC, Lucente E. Otomycosis. Ear Nose Throat J 1988; 67: 804-5, 809-10.

12 - Russell JD, Donnelly M, McShane DP, Alun-Jones T, Walsh M. What causes acute otitis externa? J Laryngol Otol 1993; 107: 898-901.

13 - Becker W, Naumann HH, Pfaltz CR. Aspectos clínicos de doenças do ouvido externo. In: Becker W, Naumann HH, Pfaltz CR, ed. Otorrinolaringologia prática - diagnóstico e tratamento. Rio de Janeiro: Revinter; 1999. p.71-82.
14 - Goodman WS, Middleton WC. The maligmant of chronic external otitis. J Otolaryngol 1984; 3: 183-6.

15 - Bluestone CD, Klein JO. Otitis media in infants and children. Philadelphia: W. B. Saunders; 1995.

16 - Almeida CIR, Almeida CR. Otite média aguda. In Campos CAH, Olival HO, ed. Tratado de otorrinolaringologia. São Paulo: Roca; 2003. v. 2, p. 21-7.

17 - Lavinsky L, Castagno LA. Epidemiologia das otites no Brasil. In: Sih T. Infectologia em otorrinopediatria. Rio de Janeiro: Revinter; 2001. p. 153-8.

18 - Miscione MC. Acute otitis media. In: Sih T, Chinski A, Eavey R. Manual of pediatríc otorhinolaryngology. Boston: International Association of Pediatric Otorhinolaringology; 2001. p. $229-233$.

19 - Lopes Filho O. Otites médias agudas; estrutura e mecanismos de defesa da orelha média. In: Lopes Filho O, Campos $\mathrm{CAH}$. Tratado de Otorrinolaríngologia. São Paulo: Roca; 1994. p. 663-75.

20 - Gonzales CDLT. Etiology of otitis media. In: Sih T, Chinski A, Eavey, R. II Manual of pediatric otorhinolaryngology. Boston: International Association of Pediatric Otorhinolaringology; 2001. p. $222-8$

21 - Bylander A. Recent advances in otitis media with effusion. Proceedings of the Second International Symposium. Columbus: Ohio State University College of Medicine. Department of Otolaryngology; 1989.

22 - Stenfors LE, Raisanen S. How long do middle ear pathogens survive in mucoid effusion material? Acta Otolaryngol 1989; 107: 244-8.

23 - Saffer M, Lubianca Neto JF, Piltcher OB, Petrillo V F. Chronic secretory otitis media: negative bacteriology. Acta Otolaryngol 1996; 116: 836-9.

24 - Saffer M, Piltcher OB, Petrillo VF. Otite média secretora. . In Campos $\mathrm{CAH}$, Olival $\mathrm{HO}$, ed. Tratado de otorrinolaringologia. São Paulo: Roca; 2003. v. 2. p. 64-71.

25 - Costa SS. Otite média crônica não colesteatomatosa. In: Campos $\mathrm{CAH}$, Olival $\mathrm{HO}$, ed. Tratado de otorrinolaringologia. São Paulo: Roca; 2003. v. 2p. 72-92.

26 - Sadde J, Luntz M, Levy D. Middle ear gas composition and middle ear aeration. Ann Otol Rhínol Laryngol 1995; 104: 369-73. 
27 - Sando I, Takahashi H, Matsune S, Aoki H. Localization of function in the Eustachian tube: hypothesis. Ann Otol Rhínol Laryngol 1994; 103: 311-4.

28 - Costa SS, Cruz OLM, Ruschel C. Otite média crônica nãocolesteatomatosa. In: Cruz OLM, Costa SS. Otologia clínica e cirúrgica. Rio de Janeiro: Revinter; 1999; cap. 9, p.181-96.

29 - Yoon TH, Paparella MM, Schachern PA, Lindgren BR. Morphometric studies of the continuum of otitis media. Ann Otol Rhinol Laryngol 1990; 99 (Suppl. 148): 23-7.

30 - Bluestone CD, Kenna MA. Workshop on chronic suppurative otitis media: Etiology and Management. August 29-30, 1985, Pittsburgh, Pennsylvania. Proceedings. Ann Otol Rhinol Laryngol 1988; 131( Suppl):1-48.

31 - Brown OE, Meyerhoff WL. Complications and sequelae of chronic suppurative otitis media. Ann Otol Rhinol Laryngol 1988; 97 (Suppl 131): 38-40.

32 - Paparella MM, Meyerholff WL. Clinical significance of granulation tissue in chronic otitis media. In: Sadé J. Cholesteatoma and mastoid surgery. Proceedings in the Second International Conference. Amsterdan: Kluger, 1982. p. 38795.

33 - Paparella MM, Oda M, Hiraide F, Brady D. Pathology of sensorineural hearing loss in otitis media. Ann Otol Rhinol Laryngol1972; 81: 632-47.

34 - Tos M. Pathology of the ossicular chain in various chronic middle ear diseases. J Laryngol Otol 1979; 93: 769-80.

35 - Browning GG, Gatehouse S, Calder IT. Medical management of chronic otitis media: a controlled study. J Laryngol Otol 1988;102: 491-5.

36 - Crowther A, Simpson D. Medical treatment of chronic otitis media: steroid or antibiotic with steroid ear-drops? Clin Otolaryngol Allied Sci 1991; 16: 142-4.

37 - Dumich PS, Harner SG. Cochlear function in chronic otitis media. Laryngoscope 1983; 93: 583-6.

38 - Paparella MM, Goycoolea MV, Bassiouni M, Koutroupas S. Silent otitis media. Clinical applications. Laryngoscope 1986; 96: $978-85$.

39 - Costa SS, Paparella MM, Schachern P, Ion TH. Chronic silent otitis media: a clinical-pathological study. A preliminar report. Rev Bras Otorrinolaringol 1991; 57: 81-4.

40 - Jahn AF. Cholesteatomas: what is it, how did it there and how do we get rid of it? Otolaryngol Clin North Am 1989; 22: 847-58.
41 - Bujía AJ, Schiling V, Holly A, Stammberger M, Kastenbauer E. Hyperproliferation-associated keratin expression in human middle ear cholesteatoma. Acta Otolaryngol 1993; 113: 3648.

42 - Caldas N. Otite média colesteatomatosa. In: Sih T. Otologia e audiologia em pediatria. Rio de Janeiro: Revinter; 1999. p. 99-105.

43 - Lopes Filho O. Colesteatoma na criança; considerações gerais. In: Lopes Filho O, Campos $\mathrm{CAH}$. Tratado de Otorrinolaringologia. São Paulo: Rocca;1994. p. 756- 62.

44 - Miniti A. Otite média crônica colesteatomatosa. In: Lopes Filho O, Campos $\mathrm{CAH}$. Tratado de Otorrinolaringologia. São Paulo: Rocca;1994. p. 745-51.

45 - Friedmann I. Tympanosclerosis. Ann Otol Rhinol Laryngol 1971; 80: 411-3.

46 - House WE, Sheehy JL. Tympanosclerosls. Arch Otolaryngol 1960; 72: 308-13.

47 - Hueb AM, Hueb MM, Silveiro JAM. Otosclerose. In: Campos $\mathrm{CAH}$, Olival HO, ed. Tratado de otorrinolaringologia. São Paulo: Roca; 2003. v. 2 p. 193-205.

48 - Davis GL. Pathology of otosclerosis: a review. Am J Otolaryngol.1987; 8: 273-81.

49 - Causse JR, Chevance LG. Sensorineural hearing loss due to cochlear otospongiosis: etiology. Otolaryngol Clin North Am 1978; 11: 125-34.

50 - Linden A, Dalligna C, Pinheiro CP. Traumatismo do osso temporal. In: Campos CAH, Olival HO, ed. Tratado de otorrinolaringologia. São Paulo: Roca; 2003. vol. 2 p. 21231.

51 - Brodie HA, Thompson TC. Management of complications from 820 temporal bone fractures. Am J Otol 1997; 18: 188-97.

52 - Cannon CR, Jahrsdoefer RA. Temporal bone fractures: review of 90 cases. Arch Otolaryngol 1983; 109: 285-8.

53 - Chang CYJ, Cass SP. Clinical forum management of facial nerve injury due to temporal bone trauma. Am J Otol 1999; 20: $96-114$.

54 - Miranda PB. Fratura do osso temporal. In: Cruz OLM, Costa SS. Otologia clínica e cirúrgica. São Paulo: Revinter; 2000. p. 419-24. 